\title{
A clinical review of obstetric hysterectomies done in medical college, Kottayam for a period of six years
}

\author{
Surya Jayaram ${ }^{1}$, Acka Priya Varghese ${ }^{2 *}$
}

\begin{abstract}
${ }^{1}$ Department of Obstetrics \& Gynaecology, Aster Women's Health, Aster Medcity, Kochi, Kerala, India
${ }^{2}$ Department of Obstetrics \& Gynaecology, Govt. Medical College, Idukki, Kerala, India
\end{abstract}

Received: 08 January 2016

Revised: 12 January 2016

Accepted: 29 January 2016

\section{*Correspondence:}

Dr. Acka Priya Varghese,

E-mail: davidsg123@yahoo.co.in

Copyright: ( ) the author(s), publisher and licensee Medip Academy. This is an open-access article distributed under the terms of the Creative Commons Attribution Non-Commercial License, which permits unrestricted non-commercial use, distribution, and reproduction in any medium, provided the original work is properly cited.

\section{ABSTRACT}

Background: Obstetric/peripartum hysterectomy is a hysterectomy performed for any indication during pregnancy, labour or puerperium. It is important to know the general incidence, changing trends and indications of this surgery. The objective of the study is to find out the incidence of obstetric hysterectomy, type of obstetric hysterectomy done, indications of the procedure, maternal clinical profile, postoperative complications and the maternal and fetal outcome.

Methods: A retrospective, descriptive case series study of all pregnant women who underwent hysterectomy in a six year period has been done.

Results: 57 women underwent hysterectomy. The incidence of obstetric hysterectomy in this study is $0.17 \%$. Mean age of the women was 30.3 years. Mean parity was two. $1.75 \%$ of cases were unbooked. $24.56 \%$ of cases underwent obstetric hysterectomy following vaginal delivery and $74.44 \%$ of cases had the procedure following abdominal route of delivery. $56.14 \%$ of cases underwent obstetric hysterectomy for postpartum hemorrhage, $36.84 \%$ underwent it for morbidly adherent placenta. $90.47 \%$ of morbidly adherent placenta had previous caesarean section as a major risk factor. $12.3 \%$ of mothers died postoperatively.

Conclusions: By good obstetric practices, proper diagnosis of morbidly adherent placenta, bringing down the number of unnecessary caesarean section the incidence of this procedure can be brought down.

Keywords: Obstetric hysterectomy, Adherent placenta, Caesarean section, Route of delivery

\section{INTRODUCTION}

Obstetric / peripartum hysterectomy is a hysterectomy performed for any indication during pregnancy, labour or puerperium. It is performed when all conservative measures have failed to achieve haemostasis, as a last resort to save a mother's life sacrificing the maternal reproductive capacity. It is important to know the general incidence, changing trends and indications of this surgery.
Review of literature reveals that several studies have been done on obstetric hysterectomy in different parts of the world. Whiteman and colleagues of the United States ${ }^{1}$ did a nationwide retrospective analysis of 48 cases of obstetric hysterectomies. Marion et $\mathrm{al}^{2}$ using the UK obstetric surveillance system did a national population based case control study. In India, Devi et $\mathrm{al}^{3}$, Richa et $\mathrm{al}^{4}$, Latika et $\mathrm{al}^{5}$, Parveen et $\mathrm{al}^{6}$, Anita et $\mathrm{al}^{7}$ have all done studies on various aspects of obstetric hysterectomies.

The present study is being undertaken with an aim to evaluate the frequency of obstetric hysterectomy, the type 
of obstetric hysterectomy, the indication of the procedure, maternal clinical profile, perioperative complications, maternal and fetal outcome following obstetric hysterectomy.

\section{METHODS}

This study was done as a descriptive retrospective case series study at Government Medical College Kottayam, Kerala, India from January 2006 to December 2011. All women who had undergone hysterectomy for any indication during pregnancy, labour and puerperium at this institution during this period was taken as study subjects with the following inclusion and exclusion criteria

All women who had undergone hysterectomy for any indication during pregnancy, (which also included those done for complications of extra uterine pregnancies or molar pregnancies or termination of pregnancy such as perforation and sepsis), labour or puerperium were included in this study.

Non pregnant women who had undergone hysterectomy for non obstetric indication such as neoplasms of uterus, or uterine adnexa were excluded from this study.

Data was obtained by reviewing the labour room register, operation register for both emergency cases and elective cases and case records. The records of all patients who had undergone obstetric hysterectomy were analysed in detail.

The clinical parameters studied were maternal age, parity, whether she was a booked case or referred case, obstetric history, route of termination of pregnancy, methods of induction of labour, indication of obstetric hysterectomy, type of obstetric hysterectomy, postoperative complications, maternal morbidity and mortality, perinatal outcome.

\section{RESULTS}

Table 1: Route of delivery.

\begin{tabular}{|lll|}
\hline No. & Route of delivery & Number(Percentage) \\
\hline 1 & Vaginal route & $14(24.56 \%)$ \\
\hline 2 & Abdominal route & $43(75.44 \%)$ \\
\hline $2(a)$ & Caesarean section & $36(63.15 \%)$ \\
\hline $2(b)$ & Hysterotomy & $2(3.51 \%)$ \\
\hline 2(c) & Laparotomy & $5(8.78 \%)$ \\
\hline
\end{tabular}

There were 57 obstetric hysterectomies done in the 6 year period of study.

The incidence of obstetric hysterectomy was found to be $0.17 \%$ i.e. 1.7 per 1000 deliveries. The incidence among vaginal deliveries was 0.6 per 1000 vaginal deliveries and incidence among caesarean deliveries was 3.2 per 1000 caesarean deliveries.

Table 2: Indications of obstetric hysterectomy.

\begin{tabular}{|ll|}
\hline Indications & Number(Percentage) \\
\hline PPH & $32(56.14 \%)$ \\
- Atonic PPH & $22(38.6 \%)$ \\
- Traumatic PPH & $10(17.54 \%)$ \\
\hline Morbidly adherent placenta & $21(36.84 \%)$ \\
\hline Rupture uterus & $4(7.02 \%)$ \\
\hline
\end{tabular}

In this study the mean maternal age was 30.3 years.

Among these 57 women 29 cases $(50.87 \%)$ were of parity two. The mean parity of women who underwent obstetric hysterectomy was around 2 . The percentage of women who underwent hysterectomy following one delivery was $6(10.53 \%)$.

Table 3: Risk factors for morbidly adherent placenta.

\begin{tabular}{|ll|}
\hline Risk factors & Number(Percentage) \\
\hline Previous 1 CS & $11(52.39 \%)$ \\
\hline Previous 2 CS & $7(33.33 \%)$ \\
\hline Previous 3 CS & $1(4.76 \%)$ \\
\hline Placenta praevia & $1(4.76 \%)$ \\
\hline No risk factor & $1(4.76 \%)$ \\
\hline
\end{tabular}

There were 30 (52.63\%) booked cases, 26 (45.6\%) referred cases and $1(1.75 \%)$ unbooked case among the 57 cases.

Table 4: Risk factors for uterine rupture.

\begin{tabular}{|ll|}
\hline Risk factors & Number \\
\hline Multipara & $1(25 \%)$ \\
\hline Multipara and oxytocin use & $2(50 \%)$ \\
\hline Prostaglandin and oxytocin use & $1(25 \%)$ \\
\hline
\end{tabular}

In these 57 patients, while studying the route of delivery, it was found that 14 of them had vaginal delivery, 36 had Caesarean section, 2 underwent hysterotomy and 5 patients had laparotomy. Among these five laparotomies four were for rupture uterus and one for hysterectomy with fetus in utero.

On analysing the indications of hysterectomies we found that 32 cases $(56 \%)$ were due to postpartum hemorrhage. Of these 32 cases, 22 cases $(38.6 \%)$ had atonic postpartum hemorrhage and 10 cases $(17.54 \%)$ had traumatic postpartum hemorrhage. In 21 cases $(36.84 \%)$ morbidly adherent placenta was the cause of obstetric hysterectomies and 4 cases $(7.02 \%)$ were due to rupture of uterus (Table 2).

While studying the risk factors associated with the 21 cases of morbidly adherent placenta, in 19 cases 
(90.47\%) of adherent placenta, previous caesarean section was found to be the most common risk factor (Table 3). History of previous one Caesarean section accounted for almost $52.4 \%$ of cases (11 cases). There were 7 cases of previous two caesarean sections. There was one case each of previous three caesarean and placenta praevia. No risk factors could be identified in one case.

Table 5: Postoperative complications.

\begin{tabular}{|ll|}
\hline Complications & $\begin{array}{l}\text { Number of cases } \\
\text { (percentage) }\end{array}$ \\
\hline Febrile morbidity & $30(52.63 \%)$ \\
\hline $\begin{array}{l}\text { Wound infection, Urinary tract } \\
\text { infection, Thrombophlebitis }\end{array}$ & $14(24.6 \%)$ \\
\hline $\begin{array}{l}\text { Pneumonitis , Pneumothorax, } \\
\text { ARDS , Post intubation laryngitis }\end{array}$ & $8(14 \%)$ \\
\hline DIC & $2(3.5 \%)$ \\
\hline Pressure sores & $2(3.5 \%)$ \\
\hline Vesicovaginal fistula & $1(1.7 \%)$ \\
\hline Acute tubular necrosis & $1(1.7 \%)$ \\
\hline Pelvic collection & $1(1.7 \%)$ \\
\hline Relaparotomy for bleeding & $2(3.5 \%)$ \\
\hline Mechanical ventilation & $14(24.6 \%)$ \\
\hline Myocardial ischaemia & $1(1.7 \%)$ \\
\hline
\end{tabular}

On analysing the four cases of rupture uterus it was found that all cases occurred in unscarred uterus. Multiparity, use of prostaglandins and oxytocin were identified as high risk factors in these cases (Table 4).

Table 6: Fetal outcome.

\begin{tabular}{|ll|}
\hline Fetal outcome & Numbers (percentage) \\
\hline Good & $43(72.88 \%)$ \\
\hline Stillborn & $7(11.86 \%)$ \\
\hline Neonatal death & $9(15.25 \%)$ \\
\hline
\end{tabular}

It was found that $80 \%$ of the cases underwent total hysterectomy while $20 \%$ underwent subtotal hysterectomy.

When we analysed the post-operative morbidity, it was found that the mean hospital stay for the study population was 13.72 days.

7 cases $(12.3 \%)$ of the study group succumbed to death in the post-operative period.

The other postoperative complications encountered in the study group are enlisted in the tabular form in Table 5.

On analysing the status of 59 neonates born to these 57 patients we found that 43 of them survived, 5 of them were still born and 9 succumbed to death in neonatal period (Table 6).

\section{DISCUSSION}

The incidence of obstetric hysterectomies in this study was 1.7 per 1000 deliveries. This was comparable with other Indian studies. ${ }^{6,7}$ Parveen et al got an incidence of 3.1 per 1000 deliveries. Similarly Anita et al got an incidence of 2.6 per 1000 deliveries.

The studies in the developed countries showed lower incidence of obstetric hysterectomies. The United Kingdom obstetric surveillance system reported an incidence of 0.41 per 1000 deliveries; the incidence in United States was 0.77 per 1000 deliveries as per Whiteman and colleagues. ${ }^{1,2}$ This may be due to the better primary and secondary prevention of the high risk factors of obstetric hysterectomies in these developed countries.

The study showed the incidence of obstetric hysterectomy among vaginal deliveries to be 0.6 per 1000 deliveries and among caesarean sections to be 3.2 per 1000 deliveries. The incidence of hysterectomy among Caesarean section deliveries were four times more than among vaginal deliveries and this difference was statistically significant ( $\mathrm{p}$ value $<0.001)$. This was comparable with the study result of Devi et al where the incidence among vaginal delivery was 0.1 per 1000 deliveries and among caesarean section was 3.9 per 1000 deliveries. $^{3}$

Therefore reducing the number of unnecessary caesarean sections will help one to restrict the number of obstetric hysterectomy.

The mean maternal age of 30.3 years got in our study was comparable to that reported by Whiteman et al as 32.3 years ${ }^{1}$.

Analysis of parity distribution showed that majority of women in this study was of parity 2 while that in other Indian studies (Anita et $\mathrm{al}^{7}$, Richa et $\mathrm{al}^{4}$ ) were of parity 3 and 4. Kerala state has the highest female literacy rate in India and hence has better utilization of family planning services. This may account for this difference.

The study revealed that $98 \%$ of cases were either booked or referred booked and only less than $2 \%$ were unbooked. This was different from other Indian studies where the number of unbooked cases was more. Anita et $\mathrm{al}^{7}$ had in their study $75.6 \%$ unbooked cases, while Parveen et $\mathrm{al}^{6}$ had $16 \%$ unbooked cases. This disparity can again be attributed to the increased awareness and utilization of health facilities by the people of Kerala.

Of 57 cases which underwent hysterectomy, $24.56 \%$ delivered vaginally and $75.44 \%$ delivered abdominally. This is comparable to UK surveillance system ${ }^{2}$ reported that $21 \%$ of cases of obstetric hysterectomies delivered vaginally and $79 \%$ delivered by Caesarean section. 
In the study $56.14 \%$ underwent the procedure due to postpartum hemorrhage with 38.6 having atonic postpartum hemorrhage, $36.84 \%$ due to morbidly adherent placenta and $7.02 \%$ underwent the same for rupture uterus. These results obtained were comparable to the results of United Kingdom obstetric surveillance system. $^{2}$ They listed the major causes of obstetric hysterectomies in the same order with postpartum hemorrhage at $53 \%$, morbidly adherent placenta at $39 \%$ and uterine rupture at $8 \%$. When we compared the results of Anita et al it was found that $41.46 \%$ had atonic postpartum hemorrhage which was comparable with this study. ${ }^{7} 36.58 \%$ in their study had rupture uterus followed by $12.2 \%$ cases of morbidly adherent placenta. This could be due to the fact that in the state of Kerala the number of grand multiparas (a main risk factor for uterine rupture) was less when compared to other states in India. Also none of the cases of previous section who had scar rupture ended in hysterectomy.

In this study population, atonic postpartum hemorrhage (38.59\%) and morbidly adherent placenta (36.84\%) were found to attribute almost equally to obstetric hysterectomy. The major risk factor for morbidly adherent placenta is previous caesarean section. Previous Caesarean section accounted as a major risk factor for $90.45 \%$ of morbidly adherent placentas in this study. Kastner et al reported that $95.6 \%$ women with placenta accreta had a history of previous cesarean delivery. ${ }^{8}$ Parveen et al reported that $83.3 \%$ of morbidly adherent placentas were due to presence of previous caesarean scar over uterus. ${ }^{6}$

The increased number of morbidly adherent placenta in this study is pointing towards increased caesarean rates in the general population. This could be an indication of changing trend in our obstetric management.

In this study we found that multiparity with use of oxytocin attributed to $50 \%$ cases of rupture of uterus. Parveen et al reported oxytocin abuse in multiparas to be responsible for $66 \%$ uterine rupture leading to obstetric hysterectomy. ${ }^{6}$

Majority in the study population underwent total hysterectomy. $80.7 \%$ underwent total abdominal hysterectomy and $19.3 \%$ underwent subtotal abdominal hysterectomy. Clarke et al and Zorlu et al found that there is no difference in blood loss and operating time on comparing total hysterectomy with subtotal hysterectomy., ${ }^{9,10}$

Febrile morbidity $(52.63 \%)$ was the most common postoperative complication seen in obstetric hysterectomies in this study. This is comparable to that reported by Latika et al $(48 \%)$ and less than that reported by Parveen et al $(63.3 \%) .^{5,6}$

Mortality rate associated with obstetric hysterectomy in the study population was $12 \%$ which was comparable with that reported by Parveen et al (10\%) and by Okafor et al $(12.5 \%){ }^{11}$

The mean hospital stay for these patients was 13.72 days comparable to Lethika et al (12 days) and Richa et al (12 days). ${ }^{4,5}$

The fetal mortality rate in our study was $27.1 \%$ which is less than that in Parveen et al $(60 \%)$ and Anita et al $(46.34 \%){ }^{6,7}$

\section{CONCLUSIONS}

Obstetric hysterectomy is a lifesaving procedure. Decision should be prompt and treated by an experienced surgeon. Every obstetrician should be trained to perform this procedure. Even so, by good obstetric practices, we should be able to bring down the number of obstetric hysterectomy. Thus the primary prevention includes good antenatal care, early detection of high risk factors, avoiding unnecessary induction of labour, judicious use of oxytocics, active management of labour, and early detection of complications, timely referral and easy availability of transport and blood transfusion facilities. Better implementation and utilisation of family planning services will reduce the number of grand multiparas.

Diagnosis of morbidly adherent placenta in the antenatal period and tackling it as an elective surgical procedure will help in reducing the morbidity and mortality associated with this surgery.

All obstetricians should be well trained in managing postpartum haemorrhage. Injudicious use of oxytocics should be avoided.

Morbidly adherent placenta is now emerging as one of the leading causes of obstetric hysterectomy. The most important risk factor for morbidly adherent placenta is previous caesarean section. Rising caesarean rates in the population is going to escalate this risk factor for obstetric hysterectomy. Data from this study as well other studies all over the world show that a caesarean section done increases the risk of obstetric hysterectomy in that pregnancy as well as in the subsequent pregnancies. All these facts point to the need of the hour, we have to reduce our caesarean rates. Thus we need to comprehensively counsel women about the risks of primary caesarean delivery and to counsel against caesarean delivery without a specific medical indication. Community education will also help us to reduce the caesarean rates.

\author{
Funding: No funding sources \\ Conflict of interest: None declared \\ Ethical approval: The study was approved by the \\ Institutional Ethics Committee
}




\section{REFERENCES}

1. Whiteman MK, Kuklina E, Hillis SD, Jamieson DJ, Meikle SF, Posner SF. Incidence and determinants of peripartum hysterectomy. Obstetrics \& Gynecology. 2006;108(6):1486-92.

2. Knight M. Peripartum hysterectomy in the UK: management and outcomes of the associated haemorrhage. BJOG: An International Journal of Obstetrics \& Gynaecology. 2007;114(11):1380-7.

3. Praneshwari Devi RK, Singh N, Singh D. Emergency Obstetric Hysterectomy, a study of 26 cases over a period of 5 years. Journal of Obstet Gynecol Ind. 2004;54:343-5.

4. Singh R, Nagrath A. Emergency obstetric hysterectomy - a retrospective study of 51 cases over a period of 5 years. Journal of Obstet Gynecol India. 2005;55(5):428-30.

5. Sahu L, Chakravertty B, Panda S. Hysterectomy for Obstetric Emergencies. Obstet Gynecol Ind. 2004;54(1):34-6.

6. Marwaha P, Kaur M, Gupta A. Peripartum hysterectomy A five year study. Journal of Obstet Gynecol India. 2008;58(6):504-6.
7. Kant A, Wadhwani K. Emergency obstetric hysterectomy. Journal of Obstet Gynecol India. 2005;55(2):132-4.

8. Kastner ES, Figueroa R, Garry D, Maulik D. Emergency peripartum hysterectomy: experience at a community teaching hospital. Journal of Obstet Gynecol. 2002;99(6):971-5.

9. Clark SL, Yeh SY, Phelan JP, Bruce S, Paul RH. Emergency hysterectomy for obstetric haemorrhage. Obstet Gynecol. 1984;64(3):376-80.

10. Zorlu CG, Turan C, Işik AZ, Danişman N, Mungan $\mathrm{T}$, Gökmen O. Emergency hysterectomy in modern obstetric practice Changing clinical perspective in time. Acta Obstet Gynecol Scand. 1998;77(2):18690 .

11. Okafor UV. Emergency Postpartum Hysterectomy for Uncontrolled Postpartum Bleeding. A Systematic Review Obstetrics \& Gynecology. 2010;116(6):1453.

Cite this article as: Jayaram S, Varghese AP. A clinical review of obstetric hysterectomies done in medical college, Kottayam for a period of six years. Int J Reprod Contracept Obstet Gynecol 2016;5:4826. 